\title{
Calculate the Area of Plane Geometry Using the SGGS-LINGKES Technique
}

\author{
Eliterius Sennen ${ }^{1}$, and Maximus Tamur ${ }^{2 *}$ \\ \{eliterius63@gmail.com¹, maximustamur@unikastpaulus.ac.id ${ }^{2}$ \} \\ Universitas Katolik Indonesia Santu Paulus Ruteng, Jl. A. Yani No 10 Ruteng ${ }^{12}$
}

\begin{abstract}
The calculation of plane geometry building areas in elementary school still relies on students' ability to remember and memorize formulas. In line with that, the use of innovative techniques such as SGGS-LINGKES has not been explored much. To fill this gap, we designed mathematics learning using SGGS-LINGKES techniques and presented them systematically. In order to achieve this goal, the literature research method has been applied for six months in the academic year 2020/2021. As a result of our research, we present detailed learning stages based on S-LINGKES, G-LINGKES, and GS-LINGKES features. This stage provides educators with insight into the media SLINGKES, G-LINGKES, and GS-LINGKES as an alternative method of teaching and learning on broad topic plane geometry. However, the summary of the effectiveness of the use of these media is not clear. Therefore, an experimental study is needed on the effect of using S-LINGKES, G-LINGKES, and GS-LINGKES media in the future.
\end{abstract}

Keywords: Area; Flat Build; SGGS-LINGKES Technique

\section{Introduction}

Guarino Guarini, mathematician and architect, asserted that architecture, a discipline primarily concerned with size, depended on geometry [1]. In line with that, the research results have confirmed that geometric skills play an essential role in developing problem-solving skills that are directly used in everyday life [2]-[8]. Thus, studying geometry means helping students improve logic, problem-solving, and reasoning skills. Geometry has wide applications in everyday life both directly and indirectly [9], [10]. There are so many models of flat shapes in real life that can be used as a context in learning geometry. This fact provides an initial hypothesis that learning geometry should not be difficult for students. This hypothesis is supported by the results of previous research that learning geometry is highly dependent on studying work examples such as the use of media that emphasizes students' physical activity [11].

Correspondingly, some researchers have used real-world contexts such as traffic signs to study triangular shapes [12]. They found that traffic sign contexts in learning geometry were very significant in developing students' geometric skills. This finding is supported by the results of other studies that the use of context in learning geometry, such as didactic games and exercises using media, can foster student academic performance [13]-[15]. However, the use of contexts far from the student's environment is one of the obstacles. In this connection, the researchers recommend the importance of making hand media that can be used as a context in learning. 
As an effort to follow up on previous research suggestions, further studies oriented to the development of hand media need to be carried out. In this connection, this literature study was conducted to design geometry learning using innovative techniques such as SGGS-LINGKES. This study will contribute to the literature, namely offering innovative work that teachers can use to help make it easier for students to understand the concept of the area of a flat shape.

\section{Methodology}

This study uses a research library as a research method. Library research is a series of activities related to collecting library data, reading and taking notes and processing the research materials. It is research that utilizes library sources to obtain research data. This research was conducted in a library that collects data on learning geometric shapes. In this study, we used a content analysis approach model. Content analysis is a research tool used to determine certain words, themes, or concepts in some qualitative data provided in the text [16]. By using content analysis, researchers can measure and analyze the existence, meaning, and relationships of certain words, themes, or concepts related to the problem of learning plane geometry.

In this study, data sources which are written materials, consist of secondary data sources obtained from libraries, online databases such as Springer, Amazon, and sage book. We have also used the google scholar database, which generally covers a broad range of topics about geometric shapes. The search results were further analyzed in-depth to find two keywords: the relation to learning the geometry of flat shapes, namely the problem related to calculating the area of a rectangular shape and calculating the area of a rectangular shape. In the literature, the presentation of the problem directly uses a formula and is expected to be memorized by students. Based on these two keywords, we compiled in detail the innovative work, namely how to calculate the Flat Area using the S-LINGKES technique. The broad categories calculate the area of a triangle shape, calculate the area of a rhombus shape, and calculate the area of a kite shape detailed in the results and discussion section.

In discussing these keywords and categories, which are the basis for learning plane geometry in elementary schools, we use the S-LINGKES technique. The S-LINGKES technique is an acronym for the word Arrangement of relations between elements or concepts and makes conclusions. The S-LINGKES technique, which is intended, is a technique of arranging various unit squares so that they can be in the form of rectangular or square shapes and then analyze the relationships between related concepts to find the area of a rectangular or square shape.

Thus, the calculation of the area of a rectangular or square flat shape using the SLINGKES technique includes the following steps: (1) preparing a number (in a certain number) of unit squares, which are made from paper or cardboard, (2) compiling a unit square exist to the point that it is in the form of a rectangular or square model, (3) analyzing the relationship between elements/concepts of length and width from the rectangular or square model formed, and (4) formulating conclusions or generalizations..

The following technique is the G-LINGKES Technique. G-LINGKES is an acronym for the word Scissors-annalist relationship between elements or concepts and makes conclusions. The G-LINGKES technique, which is meant to be a technique of cutting a flat shape in the form of a rectangle, rhombus, and/or kite through its diagonal lines in such a way that it will be divided into two equally, and each looks like a triangular shape, then analyze the 
relationship between related concepts to find the area of the shape that was formed or the original form, ends by making a conclusion.

Thus, the calculation of the area of a triangle, rhombus and kite shape using the GLINGKES technique includes the following steps: (1) preparing a rectangular or rhombus or kite shape model, which is made from manila paper or cardboard, (2) cut out existing rectangular or rhombic shapes or kites through the diagonal lines of these shapes so that they are formed into two similar and congruent triangular shapes, (3) analyze the relationship between elements / concepts from the original shape with new shapes that are formed, and (4) formulate conclusions or generalizations.

Finally, we discussed the GS-LINGKES technique. GS-LINGKES is an acronym for the word Scissors Arrangement, analyzes the relationship between elements or concepts, and makes conclusions. The GS-LINGKES technique, which is meant to be a technique of cutting a certain flat shape in the form of a triangle, parallelogram, trapezium, rhombus, kite, or circle into several pieces which can then be arranged to form a new flat shape can be in the form of rectangular or square or triangular shapes, then analyze the relationship between related concepts to find the area of the new flat shape that is formed.

Thus, the calculation of the area of a triangle, parallelogram, trapezium, rhombus, and circle using the GS-LINGKES technique includes the following steps: (1) preparing a triangular or parallelogram model or trapezium or rhombus, and / or circles, made of manila paper or cardboard, (2) cutting triangular shapes, parallelograms or trapezium or rhombus, and / or existing circles into several pieces in the form of triangles or rectangles or squares or trapezium or a circle, (3) arranging the cutout pieces in such a way that the existing pieces can form a new shape in the form of a rectangular or square or triangular shape, (4) analyzing the relationship between elements/concepts from the original shape with the new shape formed, and (5) formulating conclusions or generalizations.

\section{Result and Discussion}

\subsection{Calculating the area of a flat using the S-LINGKES technique}

In an effort to help students have a good understanding of the concept and how to calculate the area of a flat shape in the form of a rectangle or square, students need to be involved in the calculation process. Students need to be given space and opportunity to experience and do discovering concepts and ways of calculating the area of a flat shape in the form of a rectangle or square. In detail, the calculation of the area of a flat shape is through the following S-LINGKES technique by following the steps described above.

1. Calculating the area of a rectangular shape

a. Prepare several unit squares, for example, 10-unit squares, as in Figure 1

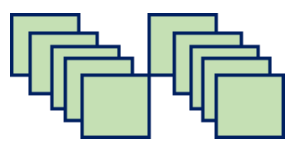

Fig 1. 10 square units

b. Construct the 10-unit squares.

c. Analyze the relationship between the elements of length and width of the rectangular shape model that is formed. This process provides four possibilities. The first 
possibility is that the process shows a $10 \times 1$ relationship; the second possibility shows a $1 \times 10$ relationship; the third probability represents a $5 \times 2$ relationship, and the fourth probability represents a $2 \times 5$ relationship.

d. Formulate conclusions

If the horizontal arrangement is called the length (p) and the vertical arrangement is called the width (1), then the area of the shapes according to the model formed is: length $\times$ width. The shapes that are formed are all rectangular. Thus, it can be concluded that: Area of the rectangle $=\mathrm{p} \times 1$.

2. Calculating the area of a square shape

a. Prepared 16 square units, as in Figure 2.

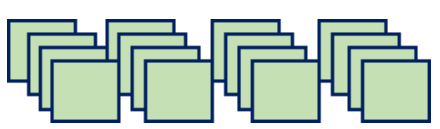

Fig 2. 16 square units

a. Construct the 16-unit squares.

Analyze the relationship between the elements of length and width of the rectangular or square model that is formed. This process provides five possibilities. The first possibility is that the process exhibits a $16 \times 1$ relationship; the second possibility shows a $1 \times 16$ relationship; the third possibility shows an $8 \times 2$ relationship; The fourth possibility represents a $2 \times 8$ relationship, and the fifth probability represents a $4 \times 4$ relationship.

b. Formulate conclusions

If the horizontal arrangement is called the length (p) and the vertical arrangement is called the width (1), then the area of the shapes according to the model formed is: $\mathrm{p} x$ 1. The shapes that are formed, there are four that are rectangular and one that is square. A $4 \times 4$ arrangement indicates that the length is the same as the width, and an arrangement like this is called a square. Thus, if $\mathrm{p}=1=\mathrm{s}$, it can be concluded that: Area of square $=$ side $\times$ side $=s 2$.

\subsection{Calculating Area of Flat with G-LINGKES Technique}

Pay attention to the calculation of the area of the flat shapes through the following GLINGKES technique by following the steps described above

1. Calculate the area of a triangle

a. A rectangular shape model made of manila paper or cardboard is prepared, as shown in Figure 3.

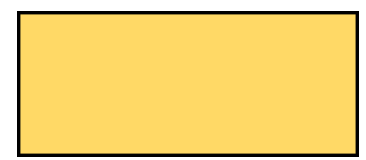

Fig 3. Rectangle

b. Cut out the existing rectangular shape through one of the diagonal lines.

c. Analyze the relationship between elements or related concepts from the original rectangular shape to the triangular shape formed as a result of cutouts. In accordance with the shape that is formed, which is in the form of two triangular shapes that are the same and congruent, then three relationships are obtained. First, the base (a) of the triangle is equal to the length of the original shape (rectangular shape); both the height $(t)$ of the triangle shape is the same as the width of the original shape 
(rectangular shape), and the third total area of the two triangular shapes that are formed is the same as the area of the original shape (rectangular shape).

d. Make conclusions

A triangular shape that is formed is half or half of the original shape (rectangular shape). In this case, the area of one of the triangles formed is equal to half of the area of the rectangle. Since the length (p) is the same as the base (a), and the width (l) is the height $(\mathrm{t})$, it can be concluded that the area of the triangle $=1 / 2($ length $\times$ width $)=$ $1 / 2$ (base $\times$ height). Thus, it can be concluded that: Area of the triangle $=1 / 2(a \times t)$.

2. Calculating the area of a rhombus shape

a. A rhombus shape is prepared, as shown in Figure 4.

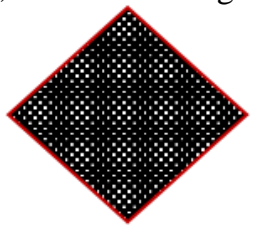

Fig 4. Rhombic

b. Cut out the existing rhombic shape through one of the diagonal lines, as shown in the picture on the side.

c. Analyze the relationship between elements or related concepts from the original rhombus shape to the triangular shape formed as a result of clippings. According to the shape that is formed, which is in the form of two triangular shapes that are the same and similar, then three relationships are obtained. First, the base (a) of the triangle is the same as the diagonal1 $(\mathrm{d} 1)$ of the rhombus $(\mathrm{a}=\mathrm{d} 1)$. Second, the height $(t)$ of the shape of the triangle is equal to half of the diagonal2 (d2) of the rhombus $(t$ $=1 / 2 \mathrm{~d} 2$ ), and the three areas of the rhombus are equal to the total area of the two triangles formed.

d. Make conclusions

Since the area of the triangle $=1 / 2(\mathrm{a} \times \mathrm{t})=1 / 2[\mathrm{~d} 1 \times(1 / 2 \mathrm{~d} 2)]$, and the area of a rhombus is twice the area of the triangle, it is found that the area of a rhombus $=2 \times$ $\{1 / 2[\mathrm{~d} 1 \times(1 / 2 \mathrm{~d} 2)]\}=1 / 2(\mathrm{~d} 1 \times \mathrm{d} 2)$. Thus, it can be concluded that the area of the rhombus shape $=1 / 2(\mathrm{~d} 1 \times \mathrm{d} 2)$.

3. Calculating the area of the kite

a. Prepared a kite shape, as shown in picture 5 .

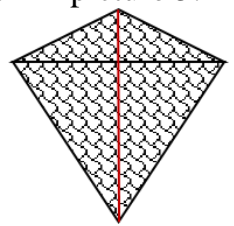

Fig 5. Kites

b. Cut out the existing kite shapes through the vertical diagonal line (the red one), as shown in the following image.

c. Analyze the relationship between elements or related concepts from the original shape in the form of a kite with the shape of two triangular shapes that are the same and congruent as a result of the cutout. In accordance with the shape that is formed, which is in the form of two triangular shapes that are the same and similar, then three relationships are obtained. First, the base (a) of the triangle is the same as the diagonal1 $(\mathrm{d} 1)$ of the kite, written $\mathrm{a}=\mathrm{d} 1$. The two heights $(\mathrm{t})$ of the triangle are equal 
to half of the diagonal2 $(\mathrm{d} 2)$ of the kite shape, $t=1 / 2 \mathrm{~d} 2$. Third, the area of the kite shape is equal to the area of the two triangles formed.

d. Make conclusions

e. Since the area of the triangle $=1 / 2(\mathrm{a} \times \mathrm{t})=1 / 2[\mathrm{~d} 1 \times(1 / 2 \mathrm{~d} 2)]$, and the area of the kite is twice the area of the triangle, it is found that the area of the kite $=2 \times 1 / 2[\mathrm{~d} 1 \times$ $(1 / 2 \mathrm{~d} 2)]=1 / 2(\mathrm{~d} 1 \times \mathrm{d} 2)$. Thus, it can be concluded that the area of the kite $=1 / 2(\mathrm{~d} 1$ $\times \mathrm{d} 2)$.

\subsection{Calculating the area of a flat using the GS-LINGKES Technique}

Pay attention to the calculation of the area of a flat shape through the following GSLINGKES technique by following the steps described above.

1. Calculating the area of a triangle shape

a. Prepared a triangular shape, as shown in Figure 6.

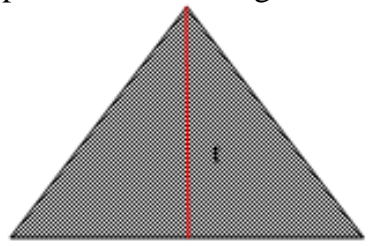

Fig 6. Kites

a. Cut out the existing triangular shape through a horizontal line bisecting the length of the line $t$, followed by marking them differently.

b. Arrange the cutout pieces as shown in the following picture.

c. Analyzing the relationship between the concepts / elements that are related from the original form in the form of a triangular shape to the rectangular shape formed as a result of the arrangement of the triangular shape pieces, and according to the shape formed in stage c), three relationships are obtained. First, the length of the rectangle formed $=$ the base of the triangle. The two widths of the rectangle formed $=$ half of the height of the triangle. The three areas of the triangle shape $=$ the area of the rectangle formed.

d. Make conclusions

Since the area of the triangle $=$ the area of the rectangle formed $=$ length $\times$ width, it is found that the area of the triangle $=\mathrm{a} \times 1 / 2 \mathrm{t}$. Thus, it can be concluded that the area of the triangle $=1 / 2(\mathrm{a} \times \mathrm{t})$.

2. Calculating the area of a parallelogram

a. A parallelogram model is prepared, as shown in Figure 7.

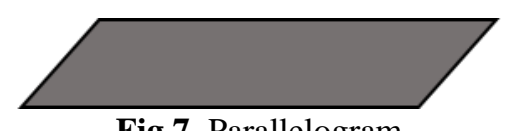

Fig 7. Parallelogram

a. Cut out the existing parallelogram shape through its height line, followed by marking it differently, as shown in the following figure.

b. Arrange the cutouts as shown in the following figure.

c. Analyzing the relationship between the concepts / elements that are related from the original form in the form of a parallelogram to the rectangular shape formed as a result of the arrangement of the parallelogram pieces, and according to the shape formed in step c), three relationships are obtained. First, the result of the arrangement of the pieces of the parallelogram is obtained a rectangular shape. Second, the 
rectangle formed has the same length as the base of the original shape (parallelogram), and the width is the same as the original height (parallelogram). The three areas of the original shape (parallelogram) are equal to the area of the rectangle formed from the pieces of the parallelogram shape.

d. Make conclusions

Since the length (p) of the rectangle formed = the length of the base (a) the parallelogram shape, and the width (l) the shape of the rectangle formed $=$ the height (t) of the parallelogram shape, it is obtained that the area of the parallelogram = length $\times$ width $=$ base $\times$ height. Thus, it can be concluded that the area of the parallelogram $=\mathrm{a} \times \mathrm{t}$.

3. Calculating the area of a rhombus shape

a. Two same rhombus shapes were prepared, as shown in Figure 8.

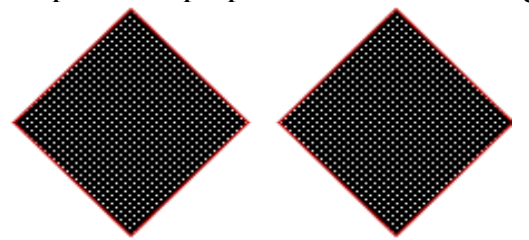

Fig 8. Parallelogram

b. Cut one of the two existing rhombic shapes through its diagonal line so that it becomes four equal and congruent right triangles, followed by marking them differently.

c. Arrange cutout pieces.

d. Analyzing the relationship between the concepts / elements related from the original form in the form of two rhombic shapes to the shape of a square shape formed as a result of the arrangement of the pieces of one rhombus shape arranged together with another rhombus shape, and according to the shape formed in step c), then we get three relationships. First. the shape formed from the combination of two rhombus shapes is a rectangular shape, whose side length $=$ the diagonal of the rhombus. Second, the area of two rhombus shapes $=$ the area of the square formed. The three areas of the squares formed $=$ diagonal $1 \times$ diagonal $2=\mathrm{d} 1 \times \mathrm{d} 2$.

e. Make conclusions

Since the area of the two rhombus shapes = the area of the square formed, it is found that the area of the rhombus shape $=1 / 2$ of the area of the square. Thus, it can be concluded that the area of the rhombus shape $=1 / 2(\mathrm{~d} 1 \times \mathrm{d} 2)$.

4. Calculating the area of a circle

a. Prepare a circle shape, as shown in figure 9.

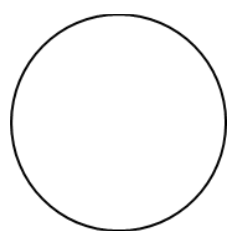

Fig 9. Circle

b. Cut through the circular diameters into several equal edges.

c. Arrange the existing grids in such a way as to form a rectangular shape.

d. Analyzing the relationship between the concepts / elements that are related from the original circular shape which is cut in the shape of a circle, and the results of the 
arrangement of the existing grids to form a rectangular shape, three relationships are obtained. First, the length of the rectangle formed $=1 / 2$ of the circumference of the circle $=1 / 2 \mathrm{~K}$. The two widths of the rectangle formed $=$ the radius of the circle $=r$. The three areas of the rectangle formed = length $\times$ width $=1 / 2 \mathrm{~K} \times \mathrm{r}$

e. Make conclusions

Since the area of the circle $=$ the area of the rectangle formed, it is found that the area of the circle $=1 / 2 \mathrm{~K} \times \mathrm{r}$, and remember that the circumference of the circle $(\mathrm{K})=2 \pi \mathrm{r}$. Thus, it can be concluded that the area of the circle $=1 / 2(2 \pi r) \times r=\pi r^{\wedge} 2$.

\section{Conclusion}

Learning activities to calculate the area of a flat shape using the SGGS-LINGKES technique allow students to experience the process of obtaining the formulas for calculating the area of a flat shape for themselves. In this case, through direct experience during learning activities, students' thinking can be directed and developed to understand mathematical concepts well, rather than just memorizing or retelling something that was told by the teacher. Thus, the management of learning should provide space and opportunities for students to allow the learning process to occur in students.

The management of mathematics learning in primary schools, which is generally still informative by relying on the ability of students to remember and memorize what is conveyed or taught by the teacher, needs to be changed and developed into meaningful learning. Meaningful learning is an activity of managing learning that provides space and opportunity for students to not only actively accept knowledge but must be able to understand it well.

\section{Acknowledgments.}

Thank you to the Santu Paulus Foundation for funding this research

\section{References}

[1] C. Cumino, M. Pavignano, M. L. Spreafico, and U. Zich, "Geometry to Build Models, Models to Visualize Geometry," Digit. Exp. Math. Educ., vol. 7, no. 1, pp. 149-166, 2021, doi: 10.1007/s40751-020-00080-6.

[2] R. Shillo, N. Hoernle, and K. Gal, "Detecting creativity in an open ended geometry environment," EDM 2019 - Proc. 12th Int. Conf. Educ. Data Min., no. Edm, pp. 408-413, 2019, doi: 10.1103/PhysRevPhysEducRes.17.010108.

[3] F. M. Adelabu, M. Makgato, and M. S. Ramaligela, "The Importance of Dynamic Geometry Computer Software on Learners ' Performance in Geometry," Electron. J. e-Learning, vol. 17, no. 1, pp. 52-63, 2019, [Online]. Available: https://files.eric.ed.gov/fulltext/EJ1216699.pdf.

[4] F. M. Adelabu and M. Makgato, "Attitudes of male and female students to dynamic geometry computer software for learning mathematics," World Trans. Eng. Technol. Educ., vol. 17, no. 3, pp. 314-319, 2019, [Online]. Available: http://www.wiete.com.au/journals/WTE\&TE/Pages/Vol.17, No.3 (2019)/17-Adelabu-F.pdf.

[5] Nurjanah, B. Latif, R. Yuliardi, and M. Tamur, "Computer-assisted learning using the Cabri 3D for improving spatial ability and self- regulated learning," Heliyon, vol. 6, no. 11, p. e05536, 2020, doi: 10.1016/j.heliyon.2020.e05536. 
[6] M. Tamur, Y. S. Kusumah, D. Juandi, T. T. Wijaya, A. Nurjaman, and A. O. Samura, "Hawthorne effect and mathematical software based learning: A meta- analysis study," J. Phys. Conf. Ser., vol. 1806, no. 1, p. 012072, 2021, doi: 10.1088/1742-6596/1806/1/012072.

[7] D. Juandi et al., "The Effectiveness of Dynamic Geometry Software Applications in Learning Mathematics: A Meta- Analysis Study,” Int. J. Interact. Mob. Technol., vol. 15, no. 02, pp. 18-37, 2021, doi: 10.3991/ijim.v15i02.18853.

[8] M. Tamur, D. Juandi, and Y. S. Kusumah, "The Effectiveness of the Application of Mathematical Software in Indonesia: A Meta-Analysis Study,” Int. J. Instr., vol. 13, no. 4, pp. 867-884, 2020, [Online]. Available: http://www.e-iji.net/dosyalar/iji_2020_4_53.pdf.

[9] S. M. Priya and S. K. Arts, "A Case Study on Analytical Geometry and its Application in Real Life,” Int. J. Sci. Dev. Res., vol. 4, no. 3, pp. 41-45, 2019.

[10] H. Serin, "Perspectives on the Teaching of Geometry: Teaching and Learning Methods," J. Educ. Train., vol. 5, no. 1, pp. 131-137, 2018, doi: 10.5296/jet.v5i1.xxxx.

[11] S. Bokosmaty, J. Sweller, and S. Kalyuga, "Learning Geometry Problem Solving by Studying Worked Examples: Effects of Learner Guidance and Expertise," Am. Educ. Res. J., vol. 52, no. 2, pp. 307-333, 2015, doi: 10.3102/0002831214549450.

[12] S. W. Siyepu and T. Mtonjeni, "Geometrical Concepts in Real-Life Context: A Case of South African Traffic Road Signs,” Proc. 20th Annu. Natl. Congr. AMESA Kimberly, no. August, pp. 213-222, 2014.

[13] Y. Roza, P. Yuanita, S. Saragih, H. Alfajri, and A. Saputra, "Computer-Based Media for Learning Geometry at Mathematics Class of Secondary Schools,” J. Educ. Sci., vol. 1, no. 1, pp. 79-91, 2017, doi: 10.31258/jes.1.1.p.79-91.

[14] D. Rohendi, S. Septian, and H. Sutarno, "The Use of Geometry Learning Media Based on Augmented Reality for Junior High School Students,” IOP Conf. Ser. Mater. Sci. Eng., vol. 306, no. 1, p. 012029, 2018, doi: 10.1088/1757-899X/306/1/012029.

[15] G. A. Totikova, A. A. Yessaliyev, N. K. Madiyarov, and N. Medetbekova, "Effectiveness of Development of Spatial Thinking in Schoolchildren of Junior Classes by Application of Plane and Spatial Modeling of Geometric Figures in Didactic Games,” Eur. J. Contemp. Educ., vol. 9, no. 4, pp. 902-914, 2020, doi: 10.13187/ejced.2020.4.902.

[16] S. Elo, M. Kääriäinen, O. Kanste, T. Pölkki, K. Utriainen, and H. Kyngäs, "Qualitative Content Analysis," SAGE Open, vol. 4, no. 1, p. 215824401452263, 2014, doi: $10.1177 / 2158244014522633$. 